\title{
Implementasi Teknologi dan Internet of Thing Untuk Otomasi Penyiraman Tanaman Berbasis Telegram di SDN1 Triharjo
}

\author{
Humairoh Ratu Ayu1', Sri Wahyu Suciyati², Hapin Afriyani ${ }^{3}$, Dwina Nurizky Syahputri ${ }^{4}$ \\ 1,2,3,4Fakultas Matematika , Universitas Lampung \\ Email: 1humairoh.ratu@fmipa.unila.ac.id, 2sri.wahyu@fmipa.unila.ac.id, \\ 3hapin.afriyani@fmipa.unila.ac.id, ${ }^{3} \mathrm{~d}$ winasyahputri844@gmail.com
}

\begin{abstract}
Abstrak
SDN 1 Triharjo berusaha meningkatkan prestasi siswa-siswi maupun sekolah dengan misi mewujudkan sekolah hijau dan sehat. Salah satu upaya yang harus dilakukan dalam mewujudkan sekolah hijau adalah merawat tanaman optik dengan membuat alat penyiram tanaman secara otomatis. Warga sekolah saat ini masih kurang sadar akan pentingnya intensitas penyiraman tanaman, karena akan berpengaruh pada pertumbuhan tanaman. Oleh sebab itu, implementasi teknologi dan internet of thing untuk otomasi penyiraman tanaman berbasis telegram dilakukan dalam kegiatan pengabdian ini. Keterlibatan langsung guru-guru dalam pelaksanan kegiatan PkM ini diharapkan dapat meningkatkan pemahaman guru-guru di SDN 1 Triharjo mengenai teknologi dan internet of thing serta kesadaran warga sekolah untuk melaksanakan perilaku peduli lingkungan dengan membuat alat sederhana yang dapat meringankan pekerjaan manusia. Terlaksananya kegiatan ini dengan baik diharapkan menjadikan salah satu nilai tambah bagi sekolah mitra.
\end{abstract}

Kata Kunci: teknologi, internet of thing, penyiram tanaman otomatis, telegram

\begin{abstract}
SDN 1 Triharjo tries to improve student and school achievement with a mission to create green and healthy schools. One of the efforts that must be made in realizing a green school is taking care of optical plants by making automatic plant sprinklers. School residents are still not aware of the importance of watering plants, because it will affect plant growth. Therefore, the implementation of technology and the internet of things (IoT) for telegram-based plant watering automation is carried out in this service activity. The direct involvement of teachers in implementing PkM activities is expected to increase understanding of yeachers in SDN 1 Triharjo about technology and internet of thing, as wll as the awareness of school residents to carry out environmental care behaviors with make simple tools that can facilitate human work. The implementation of this activity is expected to be one of the added values for partner schools.
\end{abstract}

Keywords: technology, internet of things, automatic plant sprinklers, telegram

\section{Pendahuluan}

Kelembaban tanah merupakan salah satu faktor penting yang mempengaruhi pertumbuhan tanaman (Husdi, 2018). Lembab tidaknya tanah pada tanaman bergantung pada kuantitas penyiraman. Pentingnya intensitas penyiraman pada tanaman tentu dibutuhkan perhatian khusus karena berguna untuk memantau kelembaban tanah. Air adalah salah satu komponen yang sangat vital dan dibutuhkan tanaman karena air berfungsi sebagai pelarut unsur hara, bahan fotosintesis, penetral suhu tanaman dan juga mempengaruhi kelembaban tanah (Kompas, 2020). Jika tanaman memiliki kelembaban tanah yang cukup dan proses fotosintesis dilakukan dengan sempurna, maka 
pertumbuhan tanaman juga sempurna. Namun, jika kelembaban tanah pada tanaman kurang dan proses fotosintesis terganggu, maka pertumbuhan tanaman juga ikut terganggu sehingga menyebabkan hasil tanaman berkualitas rendah (Harwati, 2007). Oleh karena itu, diperlukan suatu sistem monitoring dan kontrol yang dapat menyelesaikan permasalahan tersebut.

Perkembangan teknologi yang begitu pesat membuat peneliti-peneliti di Indonesia memanfaatkannya dalam melakukan inovasiinovasi di berbagai bidang (Serikul et al., 2018), contohnya bidang pertanian (Pitakphongmetha et al., 2017). Peran ilmu fisika diaplikasikan dengan bantuan teknologi berbasis internet of thing untuk memonitoring serta mengontrol kelembaban tanah pada tanaman dan ketinggian level air pada bak penampung. Berdasarkan hal tersebut pemanfaatan teknologi dan internet of thing dapat menjadi solusi untuk memantau dan mengontrol parameter-parameter pertanian secara real time tanpa harus datang ke lokasi.

Kegiatan PkM ini ditujukan untuk membina warga SDN 1 Triharjo dalam menerapkan teknologi dan internet of thing dengan membuat alat penyiram tanaman otomatis yang dapat dikontrol melalui aplikasi telegram. Teknologi ini tentu dapat membantu meringankan pekerjaan warga sekolah dalam menyiram tanaman, sehingga warga sekolah dapat memanfaatkan waktunya untuk melakukan hal lain tanpa perlu khawatir dengan kondisi tanamannya. Pada kegiatan PkM ini masyarakat akan diberikan pengetahuan dan keterampilan untuk mengoperasikan sistem tersebut, termasuk teknik perawatannya (maintenace) agar sistem yang dibuat dapat dimanfaatakan secara berkesinambungan. Kegiatan PkM ini sangat mendukung salah satu Misi SDN 1 Triharjo yaitu "Mewujudkan sekolah hijau dan sehat".

\section{Metode}

Kegiatan pengabdian ini terdiri dari: (i) perencanaan kegiatan pengabdian, (ii) pelaksanaan kegiatan pengabdian, (iii) evaluasi kegiatan pengabdian. Tahap persiapan meliputi berbagai kegiatan seperti membuat persentasi materi kegiatan dan menyiapkan berbagai alat dan bahan yang diperlukan untuk merancang sistem alat penyiram tanaman otomatis. Materi kegiatan akan dibuat dalam bentuk video, dan slide presentasi sehingga warga SDN 1 Triharjo memahami dengan baik mengenai pengoperasian sistem alat penyiram tanaman otomatis. Tahap selanjutnya adalah pelaksanaan kegiatan. Tahap ini dilakukan dengan dua metode utama yaitu sosialisasi dan praktik secara teknis. Sosialisasi bertujuan untuk memberikan pemahaman dan pengetahuan secara menyeluruh bahwa teknologi dan internet dapat dimanfaatkan dalam bidang pertanian, termasuk memberikan penjelasan ilmiah bagaimana sistem alat penyiram tanaman otomatis ini bekerja. Praktik secara teknis ditujukan agar warga sekolah dapat mengoperasikan sistem alat penyiram tanaman otomatis dengan benar. Selain itu, warga sekolah juga dapat mengetahui manfaat penyiraman terhadap pertumbuhan tanaman. Tahap akhir ialah evaluasi kegiatan. Tahap ini dilakukan dengan berdiskusi dan mengisi kuisoner yang dilakukan sebelum dan sesudah kegiatan pengabdian. Tujuan dari evaluasi yaitu untuk mendapatkan respon dari masyarakat mengenai kinerja alat dan penerimaan warga sekolah terhadap sistem alat penyiram tanaman otomatis. Adapun tahapan pelaksanaan kegiatan pengabdian dapat dilihat pada Gambar 1. 


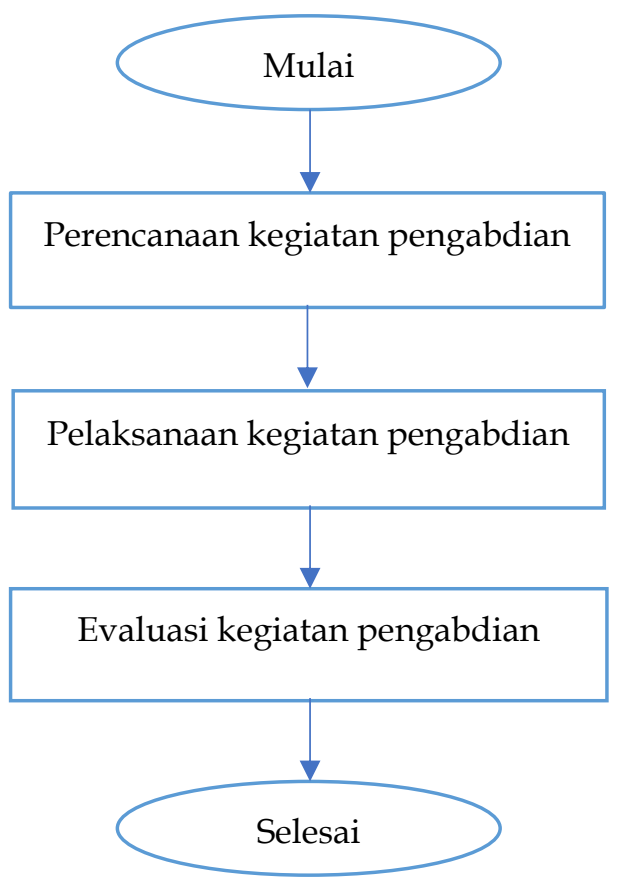

Gambar 1. Tahapan pelaksanaan kegiatan

Desain sistem alat penyiram tanaman otomatis yang akan dibuat secara sederhana ditunjukkan pada Gambar 2. Nilai kelembaban tanah pada tanaman dapat diukur menggunakan sensor soil moisture sedangkan nilai ketinggian level air diukur menggunakan sensor ultrasonik. Kedua sensor dihubungkan ke modul ESP8266 yang telah memiliki sistem WiFi didalamnya. Penyiraman otomatis dapat dilakukan dengan menghubungkan relay dan pompa air ke modul ESP8266. Pompa berfungsi untuk mengalirkan air ke tanaman secara otomatis bergantung pada batas nilai kelembaban tanah yang telah ditentukan. Jika nilai kelembaban tanah yang terukur oleh sensor soil moisture melebihi batas nilai yang telah ditentukan (tanah kering), maka pompa menyala dan mengalirkan air ke tanaman. Sedangkan jika nilai kelembaban tanah di bawah batas nilai yang telah ditentukan (tanah lembab) maka pompa mati.

Sensor ultrasonik digunakan untuk mengukur ketinggian air di dalam bak penampung, jika air dalam bak penampung di bawah batas ketinggian yang telah ditentukan, maka akan ada pemberitahuan melalui chatbot telegram. Sistem ini memanfaatkan jaringan internet agar dapat terhubung dengan smartphone menggunakan aplikasi telegram. Semua data input ataupun output dari sistem ini akan dikirimkan berupa pesan teks ke pengguna melalui aplikasi telegram secara real time. 


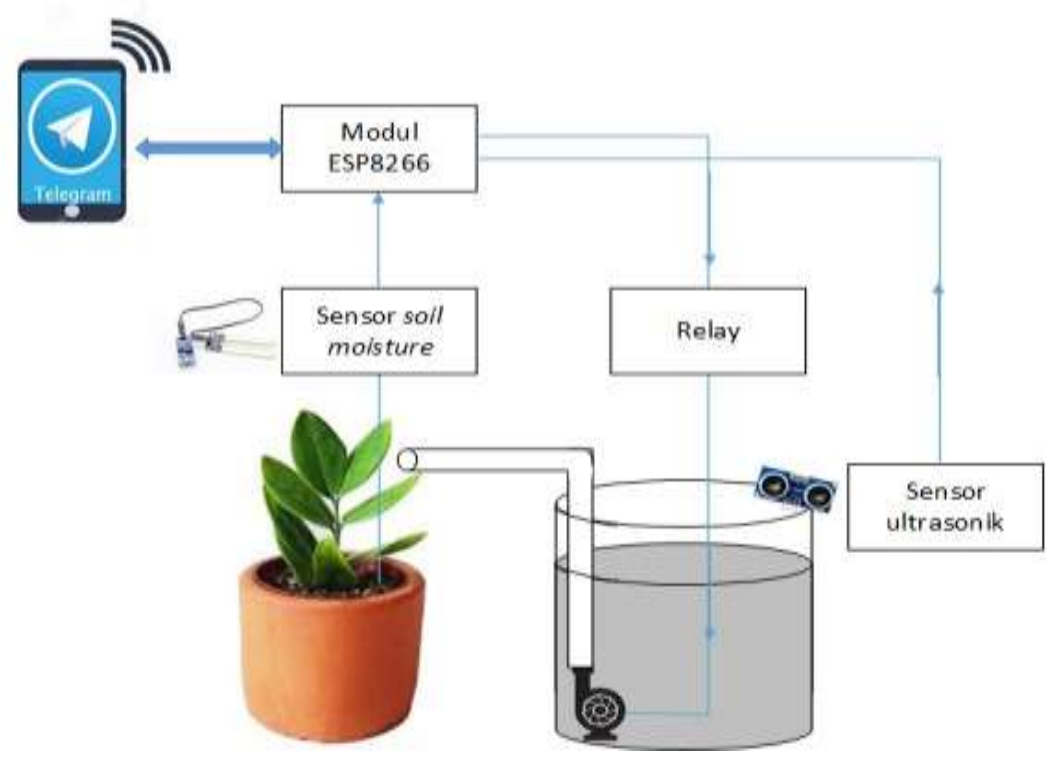

Gambar 2. Desain sistem alat penyiram tanaman otomatis

\section{Hasil dan Pembahasan}

Kegiatan pengabdian telah dilaksanakan di ruang laboratorium SDN 1 Triharjo yang diikuti oleh 14 orang guru, tidak semua guru hadir dalam kegiatan tersebut karena sedang dalam masa pemberlakuan pembatasan kegiatan masyarakat (PPKM) di kabupaten Lampung Selatan. SDN 1 Triharjo memiliki misi yaitu menjadi sekolah hijau dan sehat, oleh karena itu kegiatan pengabdian mengenai implementasi IoT untuk otomasi penyiraman tanaman berbasis telegram dirasa tepat

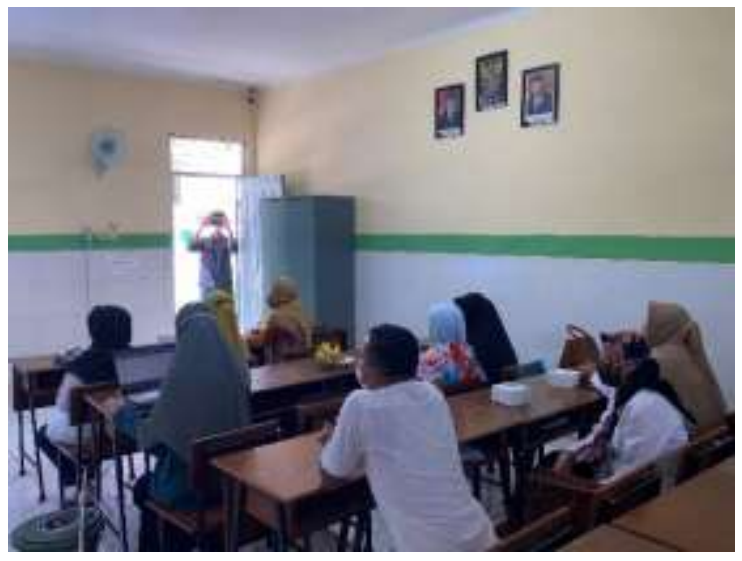

3(a) dilakukan guru-guru SDN 1 Triharjo. Hasil dokumentasi kegiatan pengabdian disajikan pada Gambar 3. Gambar 3(a) menunjukkan peserta kegiatan pengabdian. Kegiatan ini dihadiri oleh Ibu Subariyah, S.Pd., Gr. selaku kepala SDN 1 Triharjo yang memberikan sambutan serta dukungannya seperti yang disajikan pada Gambar 3(b). Dalam kegiatan ini peserta pengabdian terlibat aktif dalam setiap materi yang disampaikan, baik berupa simulasi Gambar 3(c) ataupun diskusi Gambar 3(d).

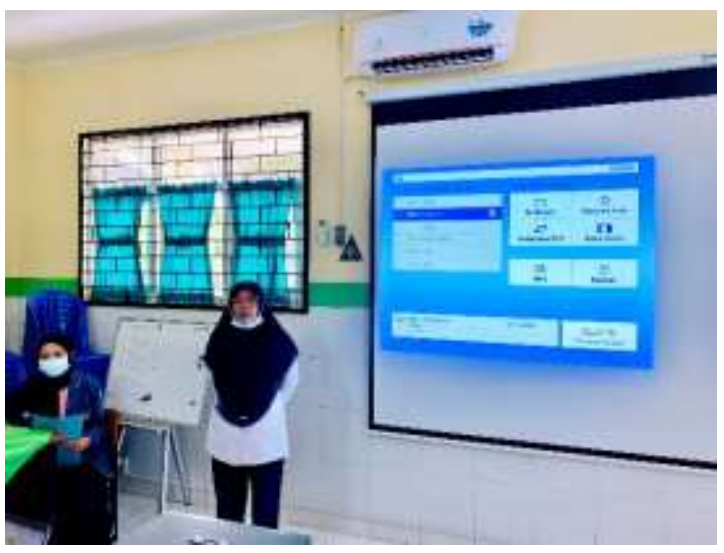

3(b) 


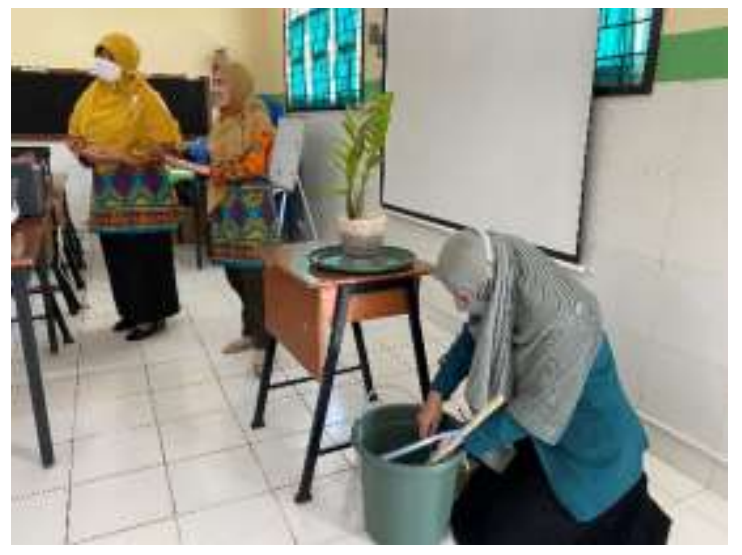

3(c)

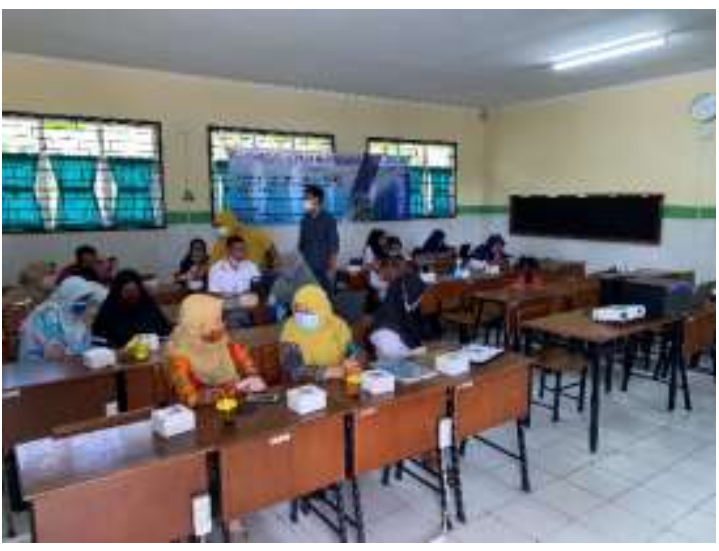

3(d)

Gambar 3. Dokumentasi kegiatan (a) Peserta pengabdian (b) sambutan kepala SDN 1 Triharjo (c) Penyampaian materi dan simulasi oleh narasumber (d) diskusi peserta.

Sebelum dilaksanakan kegiatan, peserta diminta untuk mengisi pretest (tes awal). Tes awal ini diberikan untuk menggali wawasan peserta terkait internet of thing. Setelah dilaksanakan kegiatan pengabdian, peserta diminta untuk mengisi posttest (tes akhir). Komposisi dari pertanyaan yang diajukan yaitu:

1) Apakah Anda tahu internet of thing?

2) Apakah Anda tahu salah satu teknologi yang memanfaatkan internet of thing?
3) Apakah Anda tahu alat dan bahan yang digunakan dalam merancang alat penyiram tanaman otomatis berbasis telegram?

Pilihan dari pertanyaan tersebut yaitu "Ya" atau "Tidak". Hasil evaluasi dari pretest dan posttest dianalisis kemudain dibuat dalam bentuk grafik yang ditunjukkan pada Gambar 4. Grafik tersebut merupakan perbandingan jawaban "Ya" dari peserta pada saat sebelum dan sesudah kegiatan pengabdian.

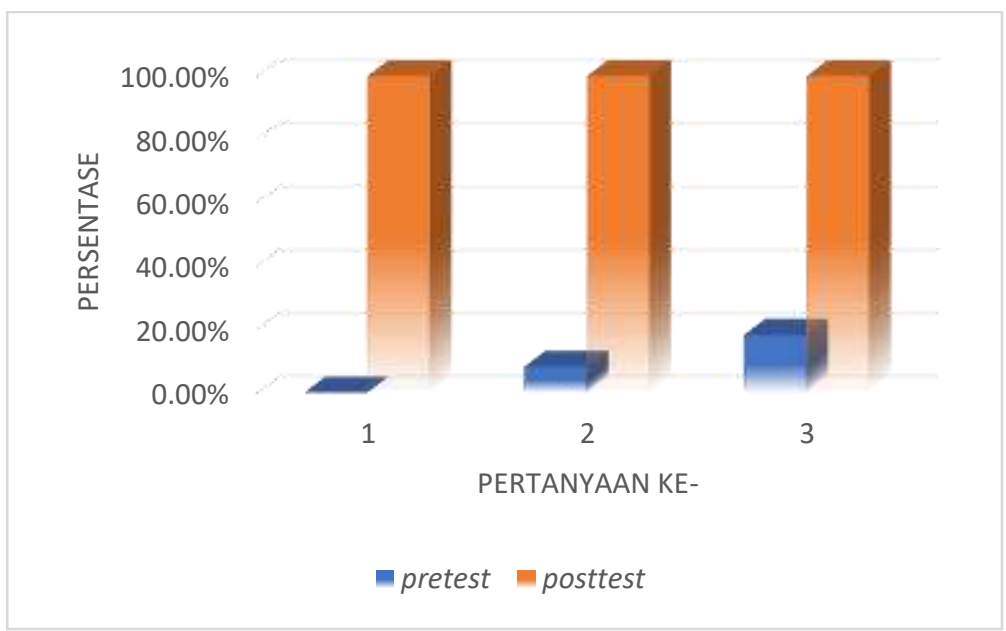

Gambar 4. Hasil pretest dan posttest 
Berdasarkan gambar 4 dapat dilihat bahwa sebelum kegiatan penganbdian dilakukan, seluruh peserta tidak mengetahui apa itu internet of thing, terbukti dengan persentase sebesar $0 \%$ untuk pertanyaan pertama. Sebesar $8,1 \%$ peserta mengetahui contoh dari teknologi yang memanfaatkan internet of thing, dan 18,2\% peserta mengetahui alat dan bahan dalam pembuatan alat penyiram tanaman otomatis berbasis telegram. Setelah dilakukan kegiatan pengabdian, tingkat pengetahuan dan pemahaman peserta jauh meningkat. Hal ini dibuktikan dengan nilai posttest yang dilakukan mencapai $100 \%$ untuk semua pertanyaan. Para peserta menunjukkan antusias dalam kegiatan pengabdian, beberapa peserta bahkan berkonsultasi terkait pembuatan alat penyiraman tanaman secara otomatis tersebut.

\section{Publikasi Online}

Kegiatan pengabdian telah dipublikasikan secara online melalui website jurusan fisika http:/ / fisika.fmipa.unila.ac.id/implementasiinternet-of-thing-melalui-kegiatanpengabdian-kepada-masyarakat-oleh-dosenfisika-di-sdn-1-triharjo-lampung-selatan/.

Bukti publikasi kegiatan secara online ditunjukkan pada Gambar 5.

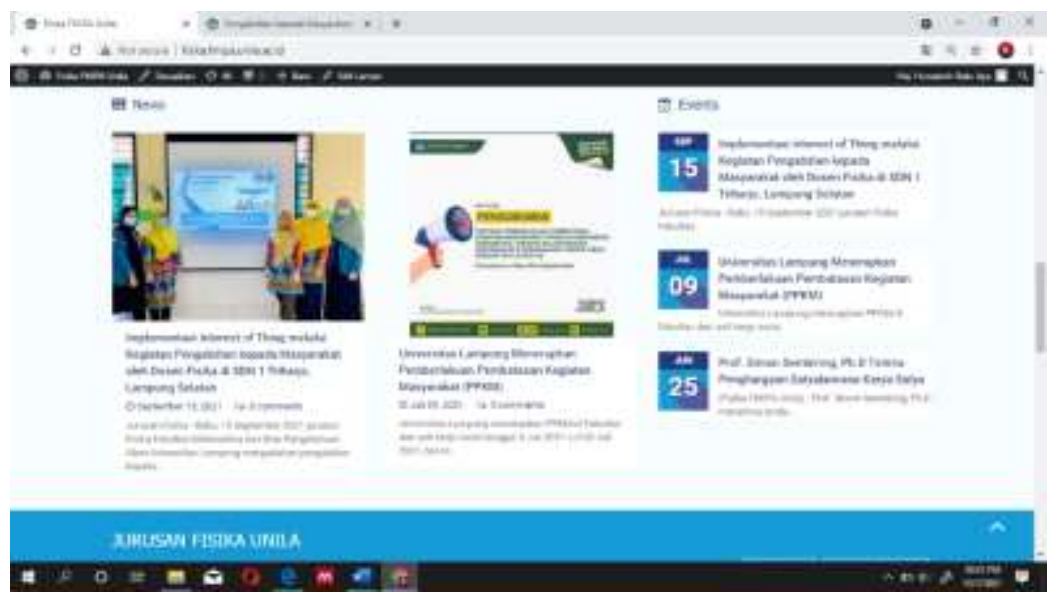

Gambar 5. Bukti publikasi secara online

\section{Kesimpulan}

Kegiatan pengabdian ini dapat meningkatkan pemahaman guru-guru di SDN 1 Triharjo mengenai teknologi dan internet of thing, serta contoh dan aplikasinya di berbagai bidang. Selain itu, juga meningkatkan kesadaran warga sekolah untuk melaksanakan perilaku peduli lingkungan dengan membuat alat sederhana yang dapat meringankan pekerjaan manusia.

\section{Ucapan Terima Kasih}

Program Pengabdian kepada Masyarakat ini didukung oleh Lembaga Penelitian dan Pengabdian kepada
Masyarakat (LPPM) Universitas Lampung melalui hibah BLU.

\section{Referensi}

Harwati, C. T. (2007). Pengaruh Kekurangan Air (Water Deficit) Terhadap Pertumbuhan dan Perkembangan Tanaman Tembakau. INNOFARM : Jurnal Inovasi Pertanian, 6(1), 44-51.

Husdi, H. (2018). Monitoring Kelembaban Tanah Pertanian Menggunakan Soil Moisture Sensor Fc-28 Dan Arduino Uno. ILKOM Jurnal Ilmiah, 10(2), 237-243. https://doi.org/10.33096/ilkom.v10i2.31 5.237-243

Pitakphongmetha, J., Boonnam, N., 
Wongkoon, S., Horanont, T., $\quad$ https://doi.org/10.1109/ICSEC.2016.785

Somkiadcharoen, D., \& Prapakornpilai, J. (2017). Internet of things for planting in smart farm hydroponics style. 20th International Computer Science and Engineering Conference: Smart Ubiquitos Computing and Knowledge, ICSEC 2016. 9872

Serikul, P., Nakpong, N., \& Nakjuatong, N. (2018). Smart Farm Monitoring via the Blynk IoT Platform. 2018 Sixteenth International Conference on ICT and Knowledge Engineering, 70-75. 